\title{
Effects of PEV Traffic Flows on the Operation of Parking Lots and Charging Stations
}

\author{
Nilufar Neyestani, Member, IEEE, Maziar Yazdani Damavandi, Member, IEEE, \\ Gianfranco Chicco, Senior Member, IEEE, and João P. S. Catalão, Senior Member, IEEE
}

\begin{abstract}
The introduction of plug-in electric vehicles (PEVs) in the electrical system is bringing various challenges. The main issue is incorporating the PEV owner's preferences in the models. One of the main attributes representing the preference of the owners is their travel purposes, impacting on the traffic flow pattern. The PEVs' traffic pattern defines the required charging schedule of the PEVs and consequently characterizes the operation of the charging facilities such as PEV parking lots (PLs). The deployment of resources such as PEV PL requires a detailed modeling of the factors affecting their operation. In this regard, this paper aims to model the power flow of the PEVs based on their traffic flow. Different travel types and purposes are considered for the PEVs traffic modeling. Two types of charging infrastructure (i.e., PLs and individual charging stations) are considered. The study is performed on a distribution network categorized based on the consumption patterns of the zones.
\end{abstract}

Index terms-Charging station (CS), parking lot (PL), plug-in electric vehicle (PEV), traffic pattern, driving behavior.

\section{NOTATION}

Capital letters denote parameters, and small ones denote variables. Minimum values are underlined, and maximum values are overlined.

\section{Subscripts}

$\begin{array}{ll}i, j & \text { Traffic zone } \\ k, k^{\prime} & \text { Network nodes } \\ l & \text { Power line } \\ \omega, \Omega & \text { Scenario and scenario set } \\ t, h & \text { Index of the time interval } \\ \text { Superscripts } & \\ \text { Agg } & \text { Aggregator } \\ \text { ar } & \text { Arrived PEVs } \\ \text { Cha/dcha } & \text { Battery charging/discharging } \\ \text { Con } & \text { Contingency Mode } \\ \text { CS } & \text { Charging Station } \\ D & \text { Demand } \\ \text { del } & \text { Delegated energy (probability of reserve call) } \\ \text { dep } & \text { Departed PEVs }\end{array}$

This work was supported by FEDER funds through COMPETE 2020 and by Portuguese funds through FCT, under Projects FCOMP-01-0124-FEDER-020282 (Ref. PTDC/EEA-EEL/118519/2010), POCI-01-0145-FEDER-016434, POCI-010145-FEDER-006961, UID/EEA/50014/2013, UID/CEC/50021/2013, and UID/EMS/00151/2013. Also, the research leading to these results has received funding from the EU Seventh Framework Programme FP7/2007-2013 under grant agreement no. 309048

N. Neyestani, M. Y. Damavandi, and J. P. S. Catalão are with INESC TEC and the Faculty of Engineering of the University of Porto, Porto 4200-465, Portugal, also with C-MAST, University of Beira Interior, Covilhã 6201-001, Portugal, and also with INESC-ID, Instituto Superior Técnico, University of Lisbon, Lisbon 1049-001, Portugal (e-mail: catalao@ubi.pt).

G. Chicco is with Politecnico di Torino, Dipartimento Energia "Galileo Ferraris", corso Duca degli Abruzzi 24, 10129 Torino, Italy, (e-mail gianfranco.chicco@polito.it).

\begin{tabular}{|c|c|}
\hline$E$ & Energy \\
\hline$E x$ & External \\
\hline$E V$ & Electric vehicle \\
\hline Fuel & Energy consumed as the fuel for the vehicle \\
\hline G2V & Grid to Vehicle \\
\hline in/out & Input/output to/from zone, Urban, or PL \\
\hline Loss & Loss of $S O C$ \\
\hline Line & Power line \\
\hline$P L$ & Parking Lot \\
\hline$R e$ & Reserve \\
\hline Sc & Scenario \\
\hline Tariff & Tariff paid by PEV owners arriving at the PL \\
\hline$T O U$ & Time of use energy price \\
\hline Urban & Urban traffic \\
\hline$V 2 G$ & Vehicle to Grid \\
\hline$v a c$ & Vacant charging points in PL \\
\hline Zone & Traffic zone \\
\hline \multicolumn{2}{|l|}{ Operators } \\
\hline$\Delta$ & Change in variable amount \\
\hline & Expected value of a variable \\
\hline \multicolumn{2}{|c|}{ Variables and Parameters } \\
\hline$c, C$ & Capacity (kWh) \\
\hline$C d$ & Cost of equipment depreciation $(€ / \mathrm{kWh})$ \\
\hline FOR & Forced outage rate $(\%)$ \\
\hline$i, I$ & Line current $(\mathrm{A})$ \\
\hline$L$ & Travel distance between zones $(\mathrm{km})$ \\
\hline$n, N$ & Number \\
\hline$n s, N S$ & Number of PEV stations \\
\hline$p, P$ & Active power $(\mathrm{kW})$ \\
\hline$q, Q$ & Reactive power (kvar) \\
\hline$r e, R E$ & Reserve $(\mathrm{kW})$ \\
\hline$R, X$ & Resistance and reactance of a line $(\Omega)$ \\
\hline$S$ & PEV speed $(\mathrm{km} / \mathrm{h})$ \\
\hline$S O C, S O C$ & State of Charge (kWh) \\
\hline$u$ & Binary variable \\
\hline$v, V$ & Voltage (V) \\
\hline$\alpha$ & Average travel time among zones $(\mathrm{h})$ \\
\hline$\beta$ & $S O C$ increase ratio in Urban traffic \\
\hline$\Gamma$ & $\begin{array}{l}\text { Charge/discharge rate in stations of Urban/PL } \\
(\mathrm{kW})\end{array}$ \\
\hline$\Delta t$ & Time step (h) \\
\hline$\Phi$ & Requirement of PEV owner for minimum $S O C$ \\
\hline$\lambda$ & SOC loss due to travel within the zone $(\%)$ \\
\hline$\eta$ & Charge and discharge efficiency $(\%)$ \\
\hline$\rho$ & Scenario probability $(\%)$ \\
\hline$\pi$ & Price $(€ / \mathrm{kWh})$ \\
\hline
\end{tabular}

\section{INTRODUCTION}

\section{A. Motivation and Background}

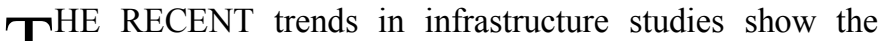
tendency towards increasing the adoption of plug-in electric vehicles (PEVs) in the everyday life. The vehicle manufacturers have spent time and budget on developing various models of PEVs to motivate the end-users to deploy PEVs instead of traditional vehicles. As the electric system 
operators try to support the PEV owners through possible incentives, the urban system planners also need to face with the preferences of the PEV owners' mobility in the urban area.

Two main solutions for providing the required charging facilities for the PEVs in the system do exist: individual charging station (CS) and PEV parking lot (PL). The provision of these facilities in the system requires a collaborative planning from electric network operator, PEV manufacturers, and urban planners. However, the widespread aspects of the problem necessitate a comprehensive study through each point of view.

Various alternatives for PEV charging are available such as battery switching. However, with recent progress in electric vehicle and its battery manufacturing, the direct charging of PEVs batteries in the plugged in position gained the highest interest in the field. Consequently, the function of PEV's PL has changed from a point of battery substitution to a medium for the direct interaction of PEVs with the grid. On these bases, the PEV owners' preferences on how to use their vehicles would be a critical issue affecting the PL's operation.

The infrastructure for the PEVs can be inadequate if the need of the owners is neglected. The PEVs traffic pattern is a way of indicating the PEVs behavior in the system. This issue becomes more dominant when the system tries to take advantage of the PEVs as well as providing them the required charging [1]. The modeling of the PEVs' traffic pattern and its incorporation in the system operation model helps considering the uncertainty of PEVs charging need, and the potential they bring to enhancing the energy management flexibility. In this regard, this paper proposes a mathematical model for modeling the PEVs traffic flow. Different levels of PEVs traffic including the PEVs' PL, CS, traveling in an area, and travel purposes has been modeled and integrated with the system operation model.

\section{B. Literature Review}

Although the electric vehicles have been the subjects of many previous studies, there are few studies that have focused on the traffic flow of PEVs in a system from both electric system and urban planning points of view. In [2] various aspects of electric mobility including power system, transport system and the technology of vehicles for efficient control of PEVs in the system were studied. The trips travelled by PEVs affect their required energy. The management of PEVs' power requirement for hybrid PEVs based on the trips they travel was studied in [3]. On the other hand, when the PEVs are interconnected to the grid, they will add to the total load of the network as they need electricity for their charging. In [4], the energy needed for the PEVs was considered as a load and was modeled based on the daily distances that the PEV users travel.

With different traffic behavior, the charging in each CS will be different, thus affecting the CS location in the grid. In [5], these effects were studied in a planning time horizon. The authors in [6] also provided the planning scheme considering the urban traffic flow of the EVs. In addition, [7] derived the behavior of the PL to be used in its allocation problem. Moreover, in [8] the traffic criteria were added to distribution system planning to provide a coupled electric and traffic network plan. In [9] the locational energy requirement of PEVs was studied by considering their random driving pattern.

The interrelation of electricity grid and transportation network for the PEVs' case is an important issue. In [10], a model for the PEVs' fleet was proposed to be used in the national energy and transportation planning. Also from the urban planning point of view, the allocation of charging infrastructures considering the traffic ways and congestions was studied in [11].

All of the abovementioned studies except for [5] only considered the grid-to-vehicle (G2V) operation of PEVs. However, the vehicle-to-grid (V2G) potential of the PEVs also proved to be an effective component in the future system.

In [12], in the planning procedure of the distributed energy resources the V2G potential and traffic pattern of PEVs were studied. Although many studies used the PEVs as their main concern of study, only a few contributions merged the simultaneous concern of PEVs traffic pattern effect on the behavior of power system components.

\section{Contributions}

This paper considers both G2V and V2G operation modes of the PEVs. Furthermore, it proposes a model for representing the operation of both PLs and CSs in the system due to different traffic behaviors. The model considers the PEV owners' preferences by taking into account the travel purposes and zonal traffic patterns, as well as modeling the desirable stay duration by considering different travel types. The requirements of PEV owners on participating in $\mathrm{V} 2 \mathrm{G}$ mode are also considered. The present model is a comprehensive model that takes into account all the aspects of PEV deployment in the system, considering that all PLs and all CSs are managed by a unique aggregator.

The paper's main contributions are:

- To model the power flow due to the traffic flow from and to different areas (urban and external) and to the PL and CS operation.

- To propose a model to derive the PL's operation with different traffic flow patterns.

- To model the market participation of an aggregator managing PLs and CSs in energy and reserve markets.

\section{Paper Organization}

The rest of the paper is organized as follows. Section II explains the main assumptions of the problem. Section III presents the traffic flow modeling. Section IV describes the mathematical optimization model for maximizing the aggregator's profit. Section V shows the numerical results. Section VI summarizes the main achievements of the study.

\section{TRAFFIC PATTERN MODEL}

With the PEV PL solution fostering the deployment of the electric vehicles, it becomes critical to examine various aspects regarding the operation of PLs; not only the network effects of the PL, but also their possible role in future electricity markets. The potential of PLs in participating in the electricity markets is considerably dependent on the availability of PEVs in the PL and their level of state of charge (SOC). The aggregation of the states of charge of all PEVs in a PL or in a zone forms the SOC 
of the PL or zone. The SOC is often expressed as a percentage of the total capacity; in this paper it is expressed in [kWh] to compare it directly with the capacity limits. Only the minimum $\underline{S O C}$ and maximum $\overline{S O C}$ are expressed in percentage, because they are applied to variable capacity values, but the percentage limits remain constant.

Higher numbers of PEVs demanding the charge affect the profit of the PL owners through selling energy to the PEV owners. In addition, the willingness of PEVs to participate in the $\mathrm{V} 2 \mathrm{G}$ mode operation, offering their level of SOC in the market, increases the profit of PLs through selling energy or reserve to the electricity market. In this regard, a proper estimation of PL's hourly potentials may help the PL operator to design a better market participation strategy.

There are various aspects affecting the potential of PL in the market, such as the number of PEVs in the PL, the PEVs stay duration and state of charge, the number of PEVs available for $\mathrm{V} 2 \mathrm{G}$, etc. The main factors affecting all these aspects are the traffic behavior of the PEVs, as well as the preferences of the PEV owners on how they are going to use their battery status. Therefore, the role of PEV's traffic pattern in PEV's market strategy becomes more dominant.

As the penetration of PEVs in the system grows, the PEV owners will have various options to charge their vehicles. As well as the increasing number of individual CSs, several PLs will also be promoted in the system. The user's choice between PLs and CSs affects the SOC availability in the PL.

Considering the above considerations, this paper investigates the effect of traffic pattern of PEVs on the PL operation in different areas of the network. The area under study is divided based on the consumption pattern of the loads on each area, which corresponds to: residential, commercial, industrial, and complex load (i.e., the combination of all load types). These consumption patterns define the travel purposes of the vehicles driving from one zone to another one. In this regards, the travel purposes of vehicles in this study are categorized into two main types, formulated after considering the outcomes of the study of travels in the UK reported in [4]:

1. Travel Type 1: Residential to commercial area travel, which includes the home-to-office travels, shopping, administrative travels, etc. This type is characterized with high commutes during traffic rush hours and a percentage of longer stay durations for the office travels.

2. Travel Type 2: Residential to industrial area travel, which indicates the traffic pattern based on the industrial working hour shifts. The travels of this type are considered to have low commute and are extended according to $24 \mathrm{~h}$ working factories.

In each area, a general-purpose travel has also been considered, named as Urban traffic. This travel also includes the energy loss of driving on the roads to reach the destination. The travel types between different areas are shown in Fig. 1.

As it is shown, zone $\# 2$ and $\# 3$ are assigned to industrial and commercial consumption patterns, respectively, and each one only has one type of travel as their arrival/departure pattern. However, zone \#1 (residential) and zone \#4 (complex, with a combination of all consumption types, i.e., residential, commercial and industrial) have both types of travel. Moreover, in each zone it is considered that some of the PEVs have a destination other than the specified zones and travel to another area, which is called External area in this study. Some vehicles also enter from the External area to the defined zones. This assumption is necessary because it is not realistic to consider that PEVs are bound to move within a specified area.

Table I represents the variants that may be found in the studies on electric vehicles, concerning charging type, operation mode and ways of managing PLs and CSs. The managing entity may be a PL, CS or PL/CS aggregator, or an individual entity such as the PEV user (for a Home CS) or an external operator (for Home or Urban CSs). Under this general scheme, it is possible to identify combined solutions in which, for example, independent operators manage the individual PLs, while all CSs could be managed by an aggregator, or other solutions. The indications provided in Table I refer to the characteristics of the system under analysis, in which the PLs and the Urban CSs are managed in an aggregate way by the same entity, and there is no Home CS. It is assumed that each zone is equipped with various numbers of PLs and Urban CSs in the area. Each PL provides G2V, while V2G is available in an optional way, i.e., subject to an additional fee. Each Urban CS provides only G2V facility; hence, it is treated as a load in the modeling.

TABle I. PResence and Management of PLs and CSs (THE INDICATIONS REFER TO THE OPTIONS USED IN THIS PAPER; THE GRAYED CELls ARE NOT RELEVANT)

\begin{tabular}{|c|c|c|c|c|c|c|}
\hline \multirow{2}{*}{$\begin{array}{c}\text { charging } \\
\text { type }\end{array}$} & \multirow{2}{*}{ mode } & \multicolumn{3}{|c|}{$\begin{array}{l}\text { aggregated } \\
\text { management }\end{array}$} & \multicolumn{2}{|c|}{$\begin{array}{c}\text { individual } \\
\text { management }\end{array}$} \\
\hline & & $\begin{array}{l}\text { unique (for } \\
\text { PLs+CSs) }\end{array}$ & PLs only & CSs only & PEV user & operator \\
\hline \multirow{2}{*}{ PL } & G2V & yes & -- & & & -- \\
\hline & V2G & optional & -- & & & -- \\
\hline \multirow{2}{*}{ Home CS } & $\mathrm{G} 2 \mathrm{~V}$ & -- & & -- & -- & -- \\
\hline & V2G & -- & & -- & -- & -- \\
\hline \multirow{2}{*}{ Urban CS } & $\mathrm{G} 2 \mathrm{~V}$ & yes & & -- & & -- \\
\hline & V2G & -- & & -- & & -- \\
\hline
\end{tabular}
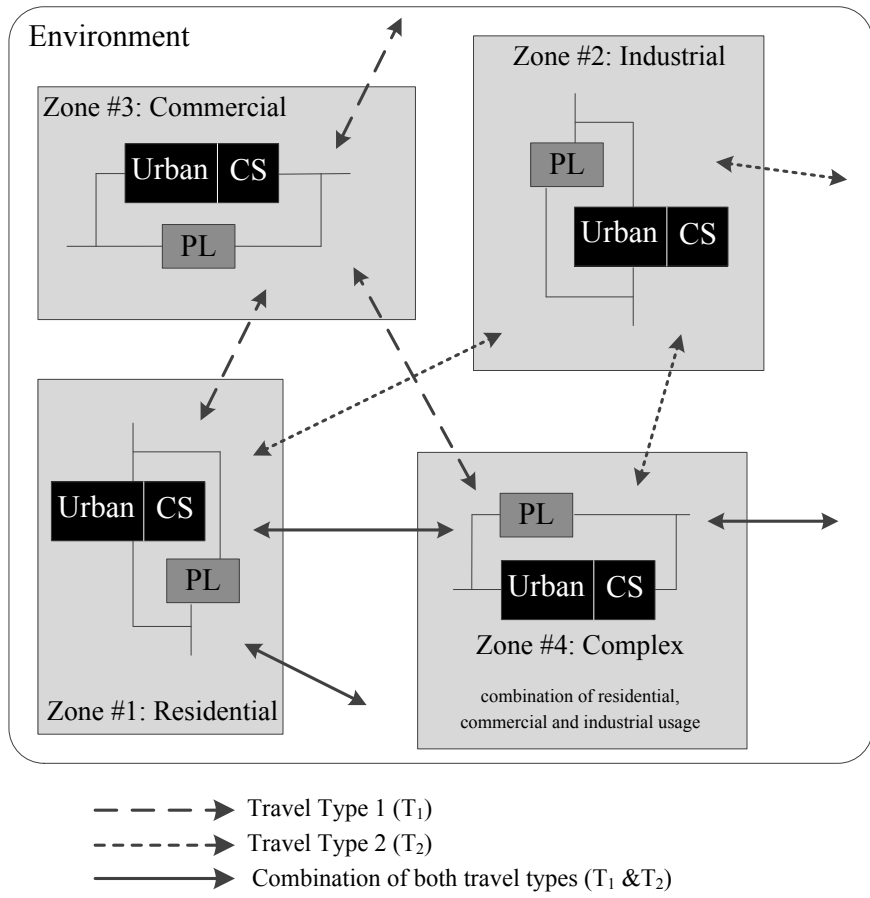
Fig. 1. Traffic flow of different travel types between consumption areas.

In each area and based on the travel type, the PEV owners' preferences on using the PL or CS as well as their charging requirements are also considered in the model. The PEVs can choose between PL and CS based on their preferred stay duration. Moreover, they can determine their minimum departure SOC requirement. For those vehicles that choose PL, the choice between $\mathrm{G} 2 \mathrm{~V}$ and $\mathrm{V} 2 \mathrm{G}$ mode is also considered. This means that not all the PEVs in the PL are obliged to participate in $\mathrm{V} 2 \mathrm{G}$ mode, but if they are willing to take part they will receive an extra payment for their battery degradation.

\section{TRAFFIC FLOW MODELING}

The traffic flow analysis is carried out by considering successive time intervals of given duration. The variable $t$ is used to represent a time interval, while the variable $\omega$ is used to represent a scenario of arrival and departure to each zone, PL and CS.

It is assumed that the arriving/departing number of PEVs and capacity to/from each zone are based on scenarios, and are considered as parameters. The traffic flow to/from each zone is depicted in Fig. 2. However, after entering the zone, the partitioning of PEVs between PL and CS would be different in each zone and is based on the PEVs' preferences in each zone; hence, the numbers of PEVs are considered as variables (e.g., by considering the scenario $\omega$, the variable $n_{i, \omega, t}^{a r, P L}$ represents the number of PEVs arriving at time interval $t$ in the PLs located in zone $i$ ).

When the pattern of arrival/departures in each zone is determined, the flow of the energy that goes with the vehicles should also be modeled. In this paper, it is assumed that in each zone the vehicles have the choice between PL and CS based on their preferences for getting charged or willingness of getting discharged. It is also assumed that the PEVs that will enter in the PL need charging, otherwise, they would not be willing to pay the PL parking fee.

Moreover, the urban driving also causes energy loss in PEV batteries. Therefore, the model also considers the energy loss due to driving in each zone. The energy flows of the PEVs as well as the interaction with the grid are shown in Fig. 3. In the figure, the total SOC of arriving vehicles from other zones and the PEVs arriving to the zone from the External area is considered as the arrival SOC of the zone $\left(\operatorname{soc}_{i, \omega, t}^{a r, Z o n e}\right)$. The arrived SOC to the zone then will be split between the PL and the Urban traffic. This means that when the vehicles arrive to the zone, they go directly to the PL or have other destinations and travel purposes in the zone. While being in the Urban area, each vehicle has the option of getting charged through fastcharging facilities provided by individual CSs in the zone. Thus, another input is added to the module, which is the average power $p_{i, \omega, t}^{i n, U \text { rban }}$ corresponding to the required energy input for charging the vehicles in the CS.

On the other hand, the PEVs that park in the PL provide $\mathrm{V} 2 \mathrm{G}$ mode as well as G2V. This assumption will result in input and output energy requirement of $\mathrm{PL}\left(p_{i, \omega, t}^{\text {in,PL }}, p_{i, \omega, t}^{\text {out }, P L}\right)$. The input/output power of the PL and input power to the CS will change the arrival SOC; hence, the departing SOC from the zone is computed from the departure SOC of Urban and PL.

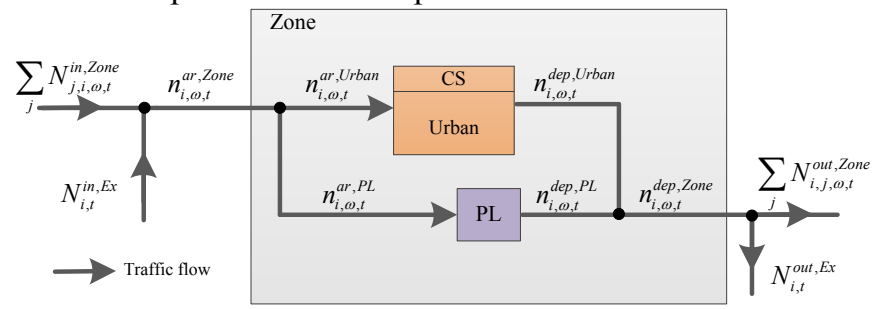

Fig. 2. Representation of the traffic flows of moving PEVs.

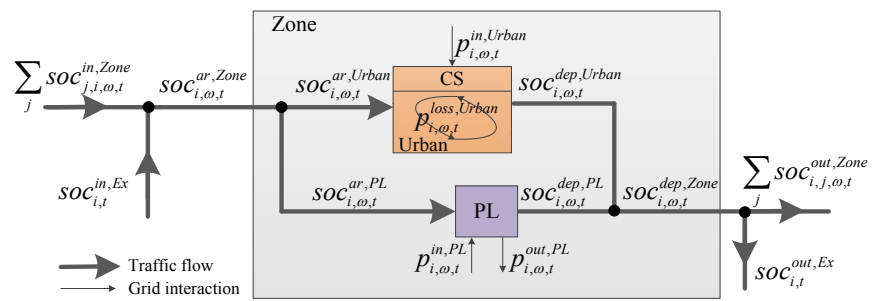

Fig. 3. Representation of the charging flows of moving PEVs.

The traffic behavior of the PEVs in each area (i.e., travel type) determines the arrival SOC to the zone and the PEV owners' preferences and travel purposes establish the arrival SOC to the PL and Urban CS. In addition, the market strategy of the PL affects its operation and consequently affects the PL's departure SOC. The departure SOC of one zone is the input SOC of another zone, interfering with the possible market strategy of other PLs in other zones. This paper provides the model to calculate the power flow based on the traffic flow and grid interaction of the electric vehicles.

The proposed model of the PEV's power flow based on their traffic flow is mathematically presented below.

\section{A. Zone traffic model}

Referring to Fig. 3, in order to construct the traffic model in each zone, it is necessary to calculate the interactions of the PEVs between zones that are determined by their number, capacity, and SOC. In this subsection the required formulation for these calculations is presented.

The duration of the travel is determined by the vehicle's speed and the distance that is traveled (1). Hence, a PEV departed from zone $i$ at time interval $t$ will arrive to zone $j$ at $h$ with a loss of fuel based on the travel's speed and distance as in (2).

$$
\begin{gathered}
\alpha_{i, j}=L_{i, j} / S_{i, j} \\
h=t+\alpha_{i, j} \Rightarrow \operatorname{soc}_{j, i, \omega, h}^{\text {in, Zone }}=\operatorname{soc}_{j, i, \omega, t}^{\text {out }, \text { One }}-N_{j, i, \omega, t}^{\text {out }, \text { Zone }} L_{i, j} P_{i, j}^{\text {Fuel }}
\end{gathered}
$$

The arrived PEVs to each zone determine the total capacity of the zone. The computed hourly arrival/departure SOC to/from each zone should not exceed the total available capacity in that zone (which is determined by scenarios) as in (3) and (4). The intention of these two constraints is to limit the computation of SOC transfer between zones with the traffic pattern scenarios.

$$
\begin{aligned}
\operatorname{SOC}_{j, i, \omega, t}^{\text {in Zone }} & \leq C_{j, i, \omega, t}^{\text {in,Zone }} \\
\operatorname{SOC}_{i, j, \omega, t}^{\text {out }, \text { Zone }} & \leq C_{i, j, \omega, t}^{\text {out }, \text { Zone }}
\end{aligned}
$$

On entering the zone, the PEV owners have several options: to go directly to the PL, to go directly to the CS, and 
travel in the zone then go to PL, or CS. It is assumed that the PEVs' first choice in industrial, residential, and complex areas are to go to the PL as the traffic pattern in those areas suggests longer stay durations and they can benefit from participating in the V2G mode. On the other hand, based on the high commute and shorter stay duration pattern in the commercial area, the first choice of the PEVs in the commercial area is to go to the CS as their main requirement is fast charging. Anyhow, regardless of the PEVs choice inside the zone, the total number of vehicles arriving to PL or Urban should be equal to the total number of PEVs entering each zone from other zones and from the External area (5). The same reasoning is used for the arrival capacity of the PEVs in Urban and PL.

$$
n_{i, \omega, t}^{a r, P L}+n_{i, \omega, t}^{a r, U r b a n}=N_{i, \omega, t}^{i n, E x}+\sum_{j} N_{j, i, \omega, t}^{i n, Z o n e}
$$

Although the PEVs may prefer to go to the PL rather than $\mathrm{CS}$, the limited number of charging points in the PL may not correspond to all the vehicles that need a parking space for charging. Thus, in each time interval the available number of (vacant) charging points in the PL in each zone $\left(n_{i, \omega, t}^{\text {vac, } P L}\right)$ is computed from (6). Then, the arrival number of PEVs to the PL is derived from (7) based on the availability of the vacant charging points in the PL.

$$
n_{i, \omega, t}^{v a c, P L}=N S_{i}^{P L}-n_{i, \omega, t}^{P L}
$$

$$
n_{i, \omega, t}^{a r, P L}=
$$$$
\left\{\begin{array}{cl}
n_{i, \omega, t}^{v a c, P L} & \text { if } N_{i, \omega, t}^{i n, E x}+\sum_{j} N_{j, i, \omega, t}^{i n, Z o n e}>n_{i, \omega, t}^{v a c, P L} \\
N_{i, \omega, t}^{i n, E x}+\sum_{j} N_{j, i, \omega, t}^{i n, Z o n e} & \text { if } N_{i, \omega, t}^{i n, E x}+\sum_{j} N_{j, i, \omega, t}^{i n, Z o n e} \leq n_{i, \omega, t}^{v a c, P L}
\end{array}\right.
$$

In (7) it is shown that if the total number of vehicles arriving to a zone in each time interval is less than the vacant charging points in the PL, then the total arrived PEVs to the zone can enter the PL. Otherwise, only the vacant charging points will be filled with the newly arrived PEVs.

Although the number of PEVs in the PL is determined by (7), the calculation of the arrival SOC is different due to the charging/discharging of the PL in preceding time intervals and in different zones. In this regard, the arrived SOC is computed from

$$
\begin{aligned}
& \operatorname{SOc}_{i, \omega, t}^{a r, P L}= \\
& \left\{\begin{array}{cl}
\sum_{k} \Delta \operatorname{Soc}_{i, \omega, t, k}^{a r, P L} & \text { if } N_{i, \omega, t}^{i n, E x}+\sum_{j} N_{j, i, \omega, t}^{i n, Z o n e}>n_{i, \omega, t}^{v a c, P L} \\
\operatorname{SOC}_{i, \omega, t}^{i n, E x}+\sum_{j} \operatorname{SOc}_{j, i, \omega, t}^{i n, Z o n e} & \text { if } N_{i, \omega, t}^{i n, E x}+\sum_{j} N_{j, i, \omega, t}^{i n, Z o n e} \leq n_{i, \omega, t}^{v a c, P L}
\end{array}\right.
\end{aligned}
$$

In this study, a new approach is formulated to calculate the variable level of SOC of the arrival vehicles to the PL. In this approach, considering the scenario $\omega$ and the time interval $t$, the binary variable $u_{i, \omega, t, k}^{P L}$ is defined to represent the presence of a vacant charging point in node $k$ (binary variable $=1$ ) or not (binary variable $=0$ ) in the PLs of zone $i$. The total number of vacant charging points in the PL and the ratio of total arrival SOC and PEV numbers to the zone are then determined as in (9) and (10).

$$
\sum_{k} u_{i, \omega, t, k}^{P L}=n_{i, \omega, t}^{v a c, P L}
$$

$$
\begin{aligned}
& \Delta \operatorname{SOc}_{i, \omega, t, k}^{a r, P L}= \\
& \quad\left[\left(\operatorname{SOC}_{i, \omega, t}^{i n, E x}+\sum_{j} \operatorname{SOc}_{j, i, \omega, t}^{i n}\right) /\left(N_{i, \omega, t}^{i n, E x}+\sum_{j} N_{j, i, \omega, t}^{i n}\right)\right] u_{i, \omega, t, k}^{P L}
\end{aligned}
$$

The arrival pattern of PEVs has been modeled with arrival scenarios and PEVs preference on choosing PL. However, estimating the departing PEVs from the zone cannot be considered in the same way. This issue is more critical when computing the departure SOC. The reason is that the arrival SOC is also affected by the charging/discharging in the PL or CS. In this regard, the following approach is adopted to calculate the number, capacity, and SOC of the PEVs. Without loss of generality, the formulation is illustrated only for the SOC.

In (11) it is shown that the departure SOC of PL and Urban will form the departure SOC that goes out from a zone to the External area or other zones. The equations (12) and (13) show that, at each time interval, the departed SOC of the Urban and PL are proportional to the level of SOC in the PL or Urban, multiplied by the number of outgoing PEVs from the zone and the total number of existing PEVs in the zone.

$$
\begin{aligned}
& \operatorname{soc}_{i, \omega, t}^{\text {dep }, P L}+\operatorname{soc}_{i, \omega, t}^{d e p, U r b a n}=\operatorname{soc}_{i, \omega, t}^{\text {dep }, \text { Zone }}=\operatorname{soc}_{i, \omega, t}^{\text {out Ex }}+\sum_{j} \operatorname{soc}_{i, j, \omega, t}^{\text {out }, \text { one }} \\
& \operatorname{soc}_{i, \omega, t}^{\text {dep Urban }}=\operatorname{soc}_{i, \omega, t}^{\text {Urban }} . \\
& \frac{\left(N_{i, \omega, t}^{\text {out Ex }}+\sum_{j} N_{i, j, \omega, t, t}^{\text {out Zone }}\right)}{\sum_{h}\left(N_{i, \omega, h}^{\text {in, Ex }}+\sum_{j} N_{i, j, \omega, h}^{\text {in, Zone }}-N_{i, \omega, h}^{\text {out Ex }}-\sum_{j} N_{i, j, \omega, h}^{\text {out }, \text { zone }}\right)+N_{i, \omega, t=1}^{P L}+N_{i, \omega, t=1}^{\text {Uriban }}} \\
& \operatorname{soc}_{i, \omega, t}^{d e p, P L}=\operatorname{soc}_{i, \omega, t}^{P L} . \\
& \frac{\left(N_{i, \omega, t}^{\text {out }, \text { Ex }}+\sum_{j} N_{i, j, \omega, t}^{\text {out Zone }}\right)}{\sum_{h}\left(N_{i, \omega, h}^{i n, E x}+\sum_{j} N_{i, j, \omega, h}^{\text {in,Zone }}-N_{i, \omega, h}^{\text {out }, E x}-\sum_{j} N_{i, j, \omega, h}^{\text {out Zone }}\right)+N_{i, \omega, t=1}^{P L}+N_{i, \omega, t=1}^{\text {Urban }}}
\end{aligned}
$$

After calculating the departure SOC of the PL and Urban, it should be determined what share of the departure SOC goes to another zone and how much travels to the External area. This allotment is done using (14) and (15).

$$
\begin{aligned}
& \operatorname{soc}_{i, \omega, t}^{\text {out }, E x}=\left(N_{i, \omega, t}^{\text {out }, E x} /\left(N_{i, \omega, t}^{\text {out }, E x}+\sum_{j} N_{i, j, \omega, t}^{\text {out Zone }}\right)\right) \operatorname{soc}_{i, \omega, t}^{\text {dep }, \text { Zone }} \\
& \operatorname{soc}_{i, j, \omega, t}^{\text {out }, \text { one }}=\left(N_{i, j, t}^{\text {out Zone }} /\left(N_{i, t}^{\text {out }, E x}+\sum_{j^{\prime}} N_{i, j^{\prime}, \omega, t}^{\text {out Zone }}\right)\right) \operatorname{soc}_{i, \omega, t}^{\text {dep }, \text { Zone }}
\end{aligned}
$$

\section{B. Urban traffic model}

After entering the zone, the PEVs may lose their SOC due to driving within the zone area, or they may increase their level of SOC with entering the CS to charge. Therefore, the SOC balance within the Urban area is based on (16), where the SOC of arrived and departed vehicles are considered as well as the input power through the CSs and the efficiency taking into account the power loss due to driving within the area. 


$$
\begin{aligned}
\operatorname{SOC}_{i, \omega, t}^{\text {Urban }} & =\left.\operatorname{SOC}_{i, \omega, t_{0}}^{\text {Urban }}\right|_{t=1}+\left.\operatorname{SOc}_{i, \omega, t-1}^{\text {Urban }}\right|_{t>1}+p_{i, \omega, t}^{\text {inj,Urban }} \eta_{i}^{\text {cha,Urban }} \Delta t \\
& +\operatorname{SOc}_{i, \omega, t}^{a r, U r b a n}-\operatorname{SOc}_{i, \omega, t}^{\text {dep }, \text { Urban }}-\operatorname{Soc}_{i, \omega, t}^{\text {loss }, \text { Urban }}
\end{aligned}
$$

The loss of SOC due to driving in the Urban area is computed with

$$
\operatorname{soc}_{i, \omega, t}^{\text {loss,Urban }}=\operatorname{soc}_{i, \omega, t}^{\text {Urban }} \lambda_{i, t}^{\text {Urban }}
$$

The maximum and minimum level of SOC in the Urban area are defined by

$$
\underline{S O C}_{i}^{E V} c_{i, \omega, t}^{\text {Urban }} \leq \operatorname{SOc}_{i, \omega, t}^{\text {Urban }} \leq \overline{\operatorname{SOC}}_{i}^{E V} c_{i, \omega, t}^{\text {Urban }}
$$

It should be noted that the maximum injected energy to the PEVs through the CSs in a time interval cannot be higher than the remainder of the capacity of the PEVs in the Urban area. Thus, the total number of CSs, the total number of vehicles in each time interval, and the available capacity of the vehicles in the Urban area are compared to determine the maximum limit for power injection into the CSs. The coefficient $\beta_{i, t}^{U r b a n}$ is a factor showing the increase in willingness to charge when lower levels of SOC remain in the battery.

$$
0 \leq p_{i, \omega, t}^{i n j, U r b a n} \leq \min \left\{\Gamma_{i}^{C S} N S_{i}^{C S}, \Gamma_{i}^{C S} n_{i, \omega, t}^{\text {Urban }},\left(C_{i, \omega, t}^{\text {Urban }}-\operatorname{soc}_{i, \omega, t}^{\text {Urban }}\right) \beta_{i, t}^{\text {Urban }}\right\}
$$

In each time interval, the total number of vehicles in the Urban area follows the balance in (20). The same balance can be used for calculating the capacity of the Urban area.

$$
n_{i, \omega, t}^{\text {Urban }}=\left.N_{i, \omega, t_{0}}^{\text {Urban }}\right|_{t=1}+\left.n_{i, \omega, t-1}^{\text {Urban }}\right|_{t>1}+n_{i, \omega, t}^{\text {ar, Urban }}-n_{i, \omega, t}^{\text {dep Urban }}
$$

\section{PL traffic model}

The effect of the traffic behavior on PL's SOC has been addressed in detail in [13] and is also considered in this study. In each time interval, the SOC of the PL is affected by the charging and discharging of the PEVs, as well as the arrival/departure SOC of the PEVs (21).

$$
\begin{aligned}
\operatorname{SOc}_{i, \omega, t}^{P L} & =\left.S O C_{i, \omega, t_{0}}^{P L}\right|_{t=1}+\left.\operatorname{soc}_{i, \omega, t-1}^{P L}\right|_{t>1}+p_{i, \omega, t}^{i n, P L} \eta_{i}^{c h a, P L} \Delta t \\
& -p_{i, \omega, t}^{\text {out }, P L} \Delta t / \eta_{i}^{d c h a, P L}+\operatorname{soc}_{i, \omega, t}^{a r, P L}-\operatorname{SOc}_{i, \omega, t}^{d e p, P L}
\end{aligned}
$$

In each time interval, the total input power of the PL is constrained by the total number of vehicles in the PL multiplied by the charging rate of the PL (22). The maximum possible output power of the PL is limited by the total number of PEVs in the PL multiplied by the discharging rate of the charging point equipment, and by the departure SOC requirements of the PEV owners (23). The PEVs' preferences on their departure SOC requirements are determined by the coefficient $\phi_{i}^{P L}$.

$$
\begin{gathered}
p_{i, \omega, t}^{i n, P L} \leq \Gamma_{i}^{P L} n_{i, \omega, t}^{P L} \\
p_{i, \omega, t}^{\text {out }, P L} \leq \min \left\{\Gamma_{i}^{P L} n_{i, \omega, t}^{P L}, \operatorname{soc}_{i, \omega, t}^{P L} \phi_{i}^{P L}\right\}
\end{gathered}
$$

When the PL is participating in the reserve market as well as the energy market, the summation of PL's energy and reserve output should be less than the minimum of PL's possible charging capacity and the available SOC in the PL to be offered in the market (24).

$$
p_{i, \omega, t}^{\text {out }, P L} \Delta t+r_{i, \omega, t}^{\text {out }, P L} \Delta t \leq \min \left\{\Gamma_{i}^{P L} n_{i, \omega, t}^{P L}, \operatorname{SOc}_{i, \omega, t}^{P L} \kappa_{i}^{P L}\right\}
$$

Like the urban area, the PL's SOC is limited to the maximum and minimum percentage of total PL's capacity (25).

$$
\underline{S O C}_{i}^{E V} c_{i, \omega, t}^{P L} \leq \operatorname{SOc}_{i, \omega, t}^{P L} \leq \overline{\operatorname{SOC}}_{i}^{E V} c_{i, \omega, t}^{P L}
$$

The number of vehicles in the PL in each time interval is calculated from (26) and should be less than the total number of charging points in the PL as in (27).

$$
\begin{gathered}
n_{i, \omega, t}^{P L}=\left.N_{i, \omega, t_{0}}^{P L}\right|_{t=1}+\left.n_{i, \omega, t-1}^{P L}\right|_{t>1}+n_{i, \omega, t}^{a r, P L}-n_{i, \omega, t}^{d e p, P L} \\
n_{i, \omega, t}^{P L} \leq N S_{i}^{P L}
\end{gathered}
$$

\section{Aggregator ObJective Model}

It is assumed a single aggregator is responsible for managing the energy flows in the system. Thus, the objective function of the aggregator is to maximize the aggregator's profit through market interactions and selling energy to the PEVs in PLs or CSs.

As shown in (28), the aggregator buys and sells energy from/to the energy market (upstream network) with energy price, but trades with PLs based on the PEV tariffs.

Based on the objective, the aggregator can make profit through selling energy to the upstream network, reserve market participation, PL's tariff, and selling energy to PEVs in the PLs. It is assumed that the energy sold to PEVs in the CSs has the same price as the energy market price, while the energy is sold to PEVs in the PLs at a price of $\pi_{i, t}^{G 2 V}$ lower than the market price. Selling to the PEV's at lower price is an incentive-based strategy taken by the PL owner to encourage the participation of PEVs in the PL. This approach in the long term would also help the PL owner to recover its maintenance costs [7].

The PL tariff and G2V/V2G prices are determined by the $\mathrm{PL}$ manager (the aggregator in this case).

Profit $^{\text {Agg }}=$

$-\sum_{t} \sum_{k} \operatorname{Cost}_{k, t}^{A g g}+\sum_{\omega} \rho_{\omega}\left[\sum_{t} \sum_{i}\left(\operatorname{Profit}_{i, \omega, t}^{P L}-\operatorname{Cost}_{i, \omega, t}^{P L}\right)\right]=$

$-\Delta t \sum_{t} \sum_{k}\left(p_{k, t}^{\text {Agg,in }}-p_{k, t}^{\text {Agg,out }}\right) \pi_{t}^{E}$

$+\Delta t \sum_{\omega} \rho_{\omega} \sum_{i} \sum_{t}\left[r_{i, \omega, t}^{\text {out }, P L} \pi_{t}^{R}+r_{i, \omega, t}^{P L} \rho_{i, t}^{\text {del }} \pi_{t}^{E}+n_{i, \omega, t}^{P L} \pi^{\text {Tariff }}\right.$

$\left.-\left(p_{i, \omega, t}^{\text {out }, P L}+r_{i, \omega, t}^{P L} \rho_{i, t}^{d e l}\right) C d-r_{i, \omega, t}^{P L} \rho_{i, t}^{d e l} F O R_{i}^{P L} \pi_{t}^{C o n}-r_{i, \omega, t}^{P L} \rho_{i, t}^{d e l} \pi_{i, t}^{V 2 G}\right)$

$\left.+p_{i, \omega, t}^{i n, P L} \pi_{i, t}^{G 2 V}-p_{i, \omega, t}^{\text {out }, P L} \pi_{i, t}^{V 2 G}\right]$

The system power flow constraints are added to the objective function. However, to assign the energy interaction of each PL or CS in each node, the following approach is adopted.

First, for each zone the total PL or urban behavior is determined using the models in Section III. Then, the expected share of each grid node $k$ (whether PL or urban) from input/output power is calculated proportional to the number of PEVs in the PL or CS (29)-(31). The same applies for the expected reserve of the PL (32).

$$
\hat{p}_{k, t}^{i n, P L}=\sum_{\omega} \rho_{\omega}\left(p_{i, \omega, t}^{i n, P L}\right) N_{i, k}^{P L} / N_{i}^{P L, \text { total }}
$$




$$
\begin{aligned}
\hat{p}_{k, t}^{\text {out }, P L} & =\sum_{\omega} \rho_{\omega}\left(p_{i, \omega, t}^{\text {out }, P L}\right) N_{i, k}^{P L} / N_{i}^{P L, \text { total }} \\
\hat{p}_{k, t}^{\text {inj,Urban }} & =\sum_{\omega} \rho_{\omega}\left(p_{i, \omega, t}^{\text {inj,Urban }}\right) N_{i, k}^{C S} / N_{i}^{C S, \text { total }} \\
\hat{r}_{k, t}^{P L} & =\sum_{\omega} \rho_{\omega}\left(r_{i, \omega, t}^{P L}\right) N_{i, k}^{P L} / N_{i}^{P L, \text { total }}
\end{aligned}
$$

The active and reactive power balance of the system is shown in (33) and (34), respectively. The power flow equation is formed as in (35) and is linearized using the technique indicated in [7].

$$
\begin{gathered}
p_{k, t}^{\text {Agg,in }}-p_{k, t}^{\text {Agg,out }}+\sum_{l} p_{k^{\prime}, k, t}^{\text {Line }}-\sum_{l}\left[p_{k, k^{\prime}, t}^{\text {Line }}+R_{k, k^{\prime}}\left(i_{k, k^{\prime}, t}\right)^{2}\right]= \\
P_{k, t}^{D}+\hat{p}_{k, t}^{\text {in,PL }}-\hat{p}_{k, t}^{\text {out }, P L}+\hat{p}_{k, t}^{\text {inj }, \text { Urban }} \\
\hat{r}_{k, t}^{P L}=\sum_{\omega} \rho_{\omega}\left(r_{i, \omega, t}^{P L}\right) N_{i, k}^{P L} / N_{i}^{P L, \text { total }} \\
v_{k, t}^{2}-2\left[R_{k, k^{\prime}}\left(p_{k, k^{\prime}, t}^{\text {Line }}-p_{k^{\prime}, k, t}^{\text {Line }}\right)+X_{k, k^{\prime}}\left(q_{k, k^{\prime}, t}^{\text {Line }}-q_{k^{\prime}, k, t}^{\text {Line }}\right)\right] \\
-Z_{k, k^{\prime}}^{2} i_{k, k^{\prime}, t}^{2}-v_{k^{\prime}, t}^{2}=0
\end{gathered}
$$

\section{NumERICAL RESULtS}

The IEEE 37 bus radial distribution test system [14] is used to model the area under study with various consumption patterns as shown in Fig. 4. The boundaries for each zone and the location of PLs and CSs are indicated in the grid. Previous studies [15] and [16] have determined the maximum possible injection from each node into the grid. This limit is considered for the determination of the maximum number of charging points in each PL.

The input data for PEVs traffic pattern (i.e., arrival/departure number, capacity and SOC of PEVs) are considered to be stochastic and modeled with different scenarios for each zone.

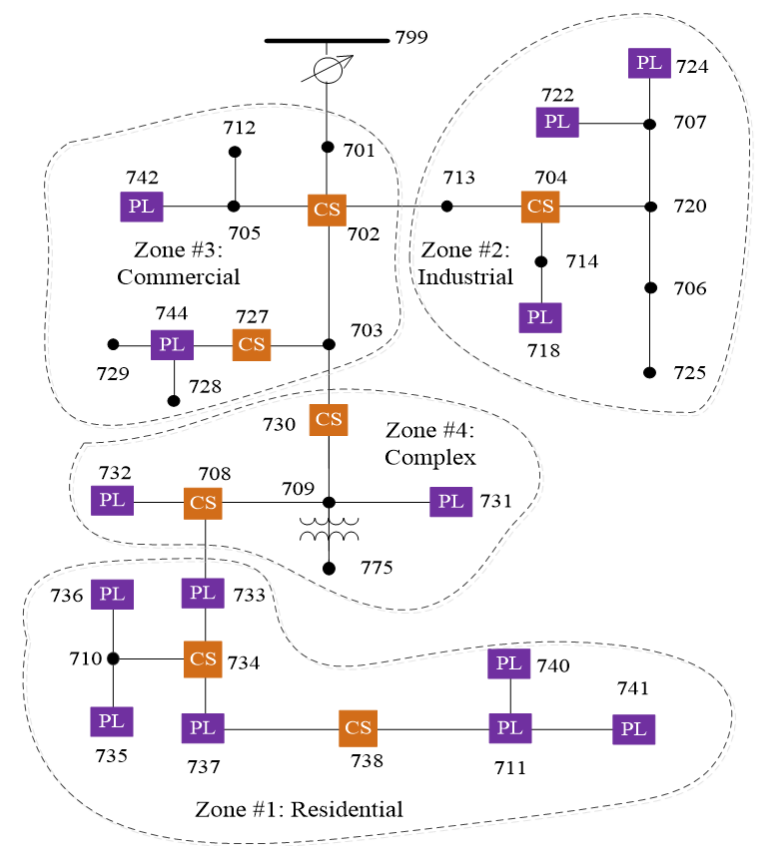

Fig. 4. IEEE 37 bus network with PLs and CSs divided based on the usage patterns.
The uncertainty characterization of the PEVs is modeled using the approach in [6] with 30 minutes' time frame. The traffic behavior of PEVs in each zone is adapted to the consumption pattern in each zone based on various traffic behavior studies including [17-19]. The travel types assumed in this study are shown in Fig. 5.

The time interval used for the analysis is 30 minutes. However, for the sake of better understanding, the figures are shown in a 24-hour frame.

The exchanges between zones are shown in Fig. 6, Fig. 7 and Fig. 8. Based on Fig. 1, the travel from zone \#1 to \#2 is travel type 1 and follows the same pattern depicted in Fig. 5. As shown in Fig. 6, the departed capacity from zone \#1 will reach zone \#2 with a time delay. However, the departed SOC from zone \#1 will reach zone \#2 both with the time delay and the loss of SOC level due to consuming the battery charge during the driving. Moreover, the driving patterns of PEVs in each zone are in accordance with the consumption pattern of the zone. It shows that the PEVs leave the residential area at the beginning of the working hours and come back at the end of the day. However, as it is assumed that the factories in the industrial zone work for three work shifts, the arrival/departure hours are more spread comparing to traffic pattern of residential-commercial travels.

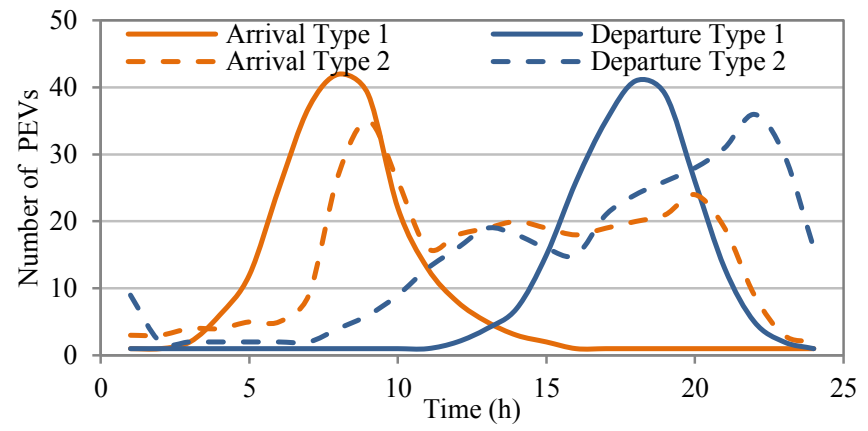

Fig. 5. Expected number of PEVs in arrival/departure of each travel type.

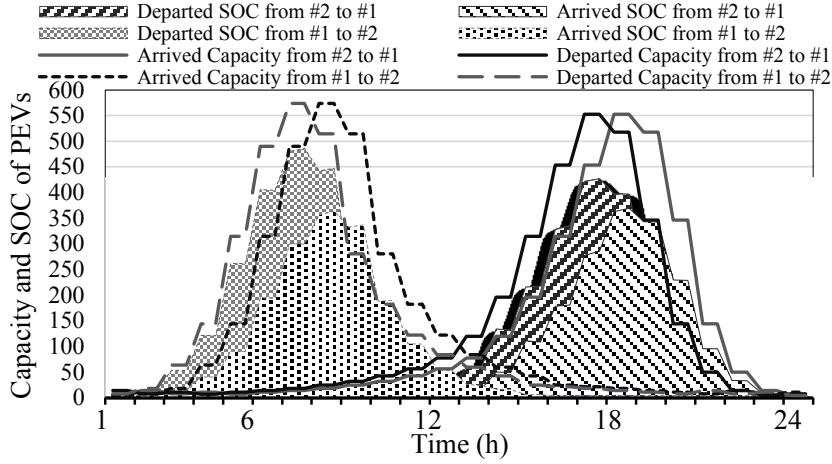

Fig. 6. Capacity and SOC flow between Zone \#1 and Zone \#2. 


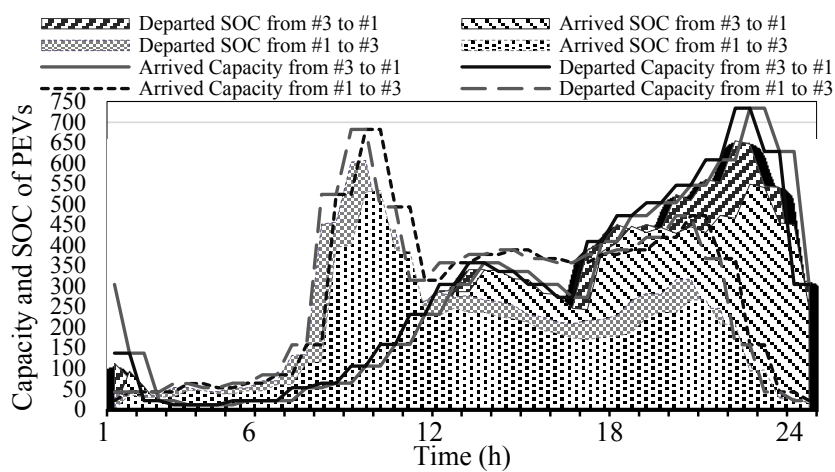

Fig. 7. Capacity and SOC flow between Zone \#1 and Zone \#3.

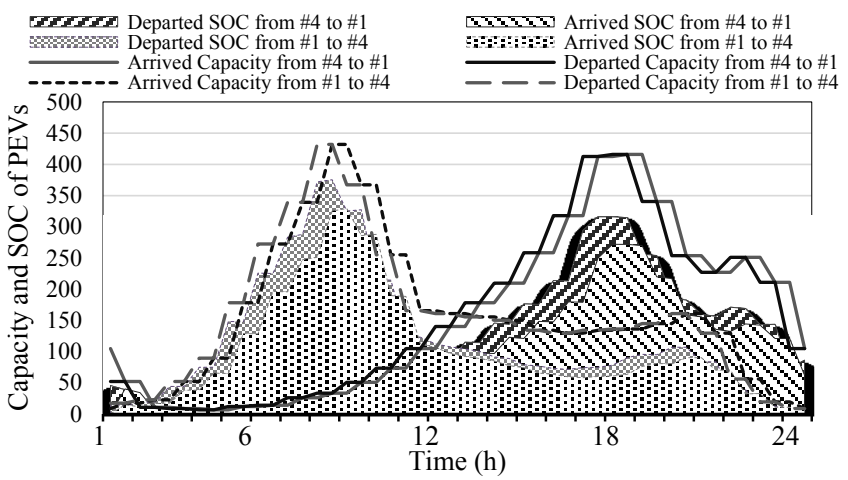

Fig. 8. Capacity and SOC flow between Zone \#1 and Zone \#4.

Data for the day-ahead market are obtained from the Spanish electricity market [20]. It is assumed that in the PL only one kind of charging point is used. Based on [21] and [22], it is assumed that the PLs have the medium-charging point at a charging rate of $11 \mathrm{~kW}$ per hour. On the other hand, the CSs are equipped with fast-charging facilities so that the vehicles would not need to stay long for getting charged. The proposed model is formulated as a mixed integer linear programming (MILP) problem and is solved with GAMS by using the CPLEX12 solver two 3.07-GHz Intel six-core processors with 100 GB of RAM, running 64-b Windows. Due to high computational model the response time of the program is about 35 minutes, which does not affect the applicability of the model.

The results for energy interaction of PEVs in each zone are shown in figures 9 to 12 . In all the figures, the total energy interaction of the PLs and CSs in each zone is shown ${ }_{2}$ as well as the energy loss in the urban driving. As it can be seen, the energy interaction of the PL is in accordance with the availability of the PEVs in the zone based on each zone's traffic pattern. In Fig. 9, in the residential area, the PL is charging during early hours in the morning when the energy price is lower, while during late hours of the day more charging is done with CSs. At hour 21, the PL injects into the grid as a compromise of energy and reserve price.

The analysis of the energy interactions in each zone can be performed with consideration of the traffic behavior. In zone \#2 with the industrial pattern, the traffic has a low commuting pattern. Moreover, the three working shifts cause higher stay durations and higher number of PEVs remaining in the area. However, charging through the PLs is mainly postponed for the lower price hours (from 1 to 7 a.m.). On the other hand, in zone \#3 where the commuting is high, both PL and CS tend to charge the PEVs based on their requirements before their departure. As higher numbers of PEVs are traveling in zone \#3, higher charging through CSs happens in this zone. Besides, higher level of urban loss is observed in this zone comparing to zone $\# 1$ and $\# 2$.

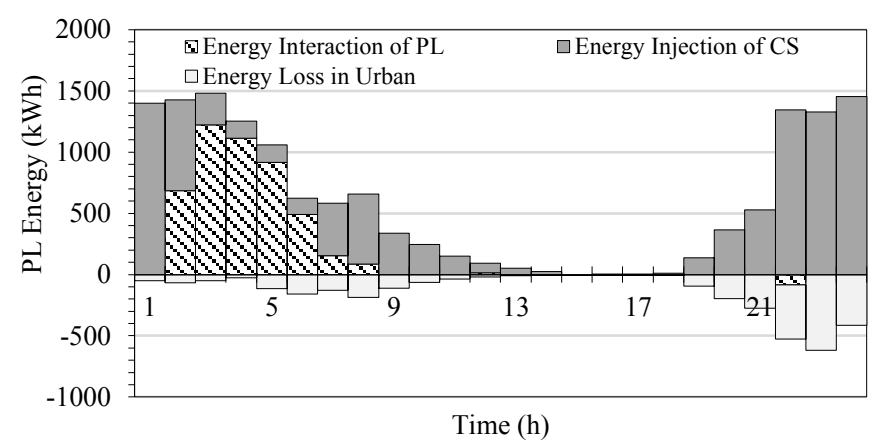

Fig. 9. Energy interactions in Zone \#1.

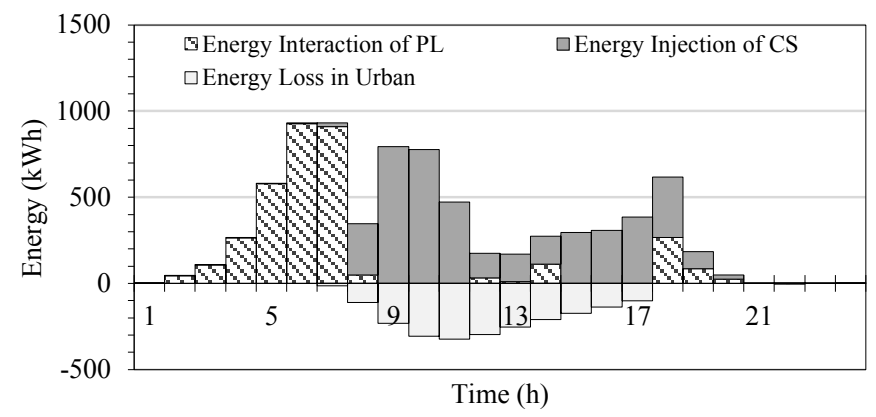

Fig. 10. Energy interactions in Zone \#2.

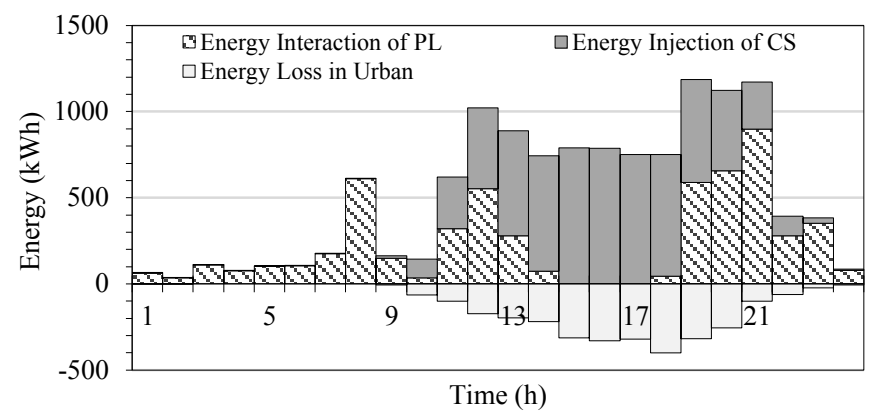

Fig. 11. Energy interactions in Zone \#3.

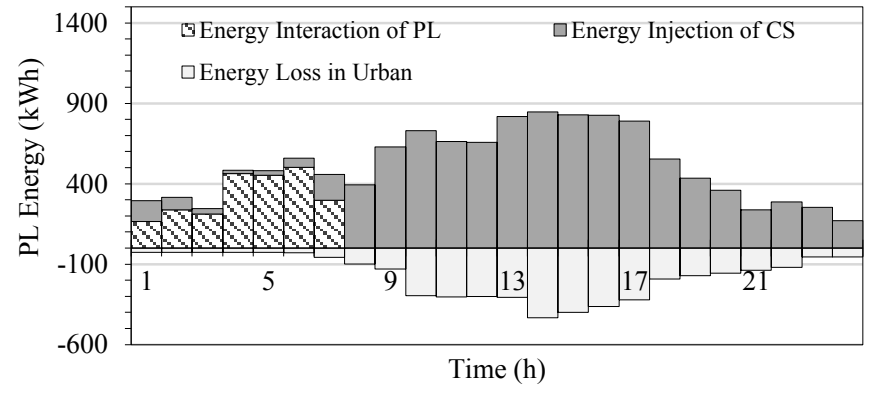

Fig. 12. Energy interactions in Zone \#4.

For zone \#4 (Fig. 12), a combination of all travel types is present in the zone, but the PL charges the PEVs only in the 
low-price hours. The reason is that based on the travels between zones, the SOC of the PEVs that reach zone \#4 is affected by the charging that they receive in other zones. Another affecting factor is the number of PL charging points versus CSs in each zone. In zones \#1 and \#2, due to low commuting and longer stay durations, the number of PL charging points is higher than in zones \#3 and \#4 where, due to high commuting pattern, the PEVs prefer to use fast charging of CSs.

The total reserve provision of PLs in each zone is shown in Fig. 13. As can be seen, the reserve provision of zone \#4 has smoother pattern comparing to the other zones. This assures the profit of PLs in zone \#4 despite of not selling energy to the PEVs. The results show that the PLs in zones \#1 and \#2 have higher amount of reserve provision due to longer stay of PEVs in the parking on the other hand, the availability of the reserve is bound to the specific hours. For zone \#3, the PLs' profit is mainly through selling energy to PLs due to shorter stay rather than providing reserve to the system.

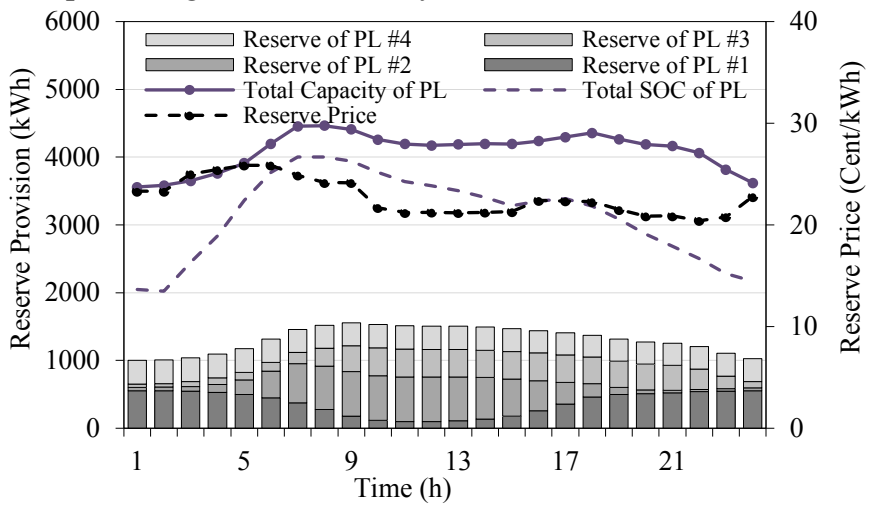

Fig. 13. Reserve provision for the system through PLs in all zones.

\section{CONCLUSIONS}

In this study, various considerations regarding the energy flown with the traffic of PEVs in a distribution system have been studied. Two types of PEV infrastructures, i.e., PLs and CSs, have been added to the grid to meet the PEV owners' preferences. PLs and CSs are managed by the same entity. The results investigated the market benefit of the energy provider (aggregator) operating those components. It was concluded that as different traffic patterns give different behavior to the PLs in each zone, different levels of flexibility will be provided for the aggregator to exploit in its market strategy. The traffic behavior of the residential and industrial zones gave the aggregator the potential of reserve market participation, while the commercial zone helped the aggregator to make profit through selling energy to high commute PEVs on their short stay. Although the problem investigated the aggregated operation of the PLs in different zones, the results show the possible cross effects of each PLs' strategy on charging the PEVs on the other PL's behavior. Moreover, it gives the insights for investment decision making for the installation of the PL based on the consumption pattern of the area. It can be concluded that if an investor decides to install a PL in a residential area it is beneficial if the reserve market participation is possible for the PL operator. On the other hand, the results suggest that deploying a combination of all possible PEV travels (as in the complex zone) gives a smooth profile to the system operator and simplifies the operation of the system.

Finally, the outcomes of this study show that the proposed model is efficient and can be used for providing the guidelines on the PEV PL planning, as well as the operation of a system with higher penetration of PEVs. The studies based on this model can be adopted to evaluate the economic aspects of the PL along with the PEV impacts on the network. Moreover, as it also considered the traffic flow of the PEVs, better insights for urban planning of PL's installation can be achieved.

\section{REFERENCES}

[1] N. S. Pearre, W. Kempton, R. L. Guensler, V. V. Elango, "Electric vehicles: How much range is required for a day's driving," Transportation Research Part C: Emerging Technologies, vol. 19, no. 6, pp. 1171-1184, 2011.

[2] M. D. Galus, R. A. Waraich, F. Noembrini, K. Steurs, G. Georges, K. Boulouchos, K. W. Axhausen, and G. Anderson, "Integrating Power Systems, Transport Systems and Vehicle Technology for Electric Mobility Impact Assessment and Efficient Control," IEEE Trans. Smart Grid, vol. 3, no. 2, pp. 934-949, 2012.

[3] Q. Gong, Y. Li, and Z. Peng, "Trip-Based Optimal Power Management of Plug-in Hybrid Electric Vehicles," IEEE Trans. Vehicular Technology, vol. 57, no. 6, pp. 3393-3401, 2008.

[4] K. Qian, C. Zhou, M. Allan, and Y. Yuan, "Modeling of Load Demand Due to EV Battery Charging in Distribution Systems," IEEE Trans. Power Syst., vol. 26, no. 2, pp. 802-810, 2011.

[5] G. Wang, Z. Xu, F. Wen, and K. P. Wong, "Traffic-constrained multi objective planning of electric-vehicle charging stations," IEEE Trans. Power Delivery, vol. 28, pp. 2363-2372, 2013.

[6] Z. Liu, F. Wen and G. Ledwich, "Optimal Planning of Electric-Vehicle Charging Stations in Distribution Systems," IEEE Trans. on Power Delivery, vol. 28, no. 1, pp. 102-110, 2013.

[7] N. Neyestani, M. Y Damavandi, M. Shafie-khah, J. Contreras, and J.P.S. Catalao, "Allocation of Plug-In Vehicles' Parking Lots in Distribution Systems Considering Network-Constrained Objectives," IEEE Trans. on Power Systems, vol. 30, no. 5, pp. 2643-2656, 2015.

[8] W. Yao et al., "A Multi-Objective Collaborative Planning Strategy for Integrated Power Distribution and Electric Vehicle Charging Systems," IEEE Trans. on Power Systems, vol. 29, no. 4, pp. 1811-1821, 2014.

[9] M. E. Khodayar, L. Wu, and M. Shahidepour, "Hourly Coordination of Electric Vehicle Operation and Volatile Wind Power Generation in SCUC," IEEE Trans. Smart Grid, vol. 3, no. 3, pp. 1271-1279, 2012.

[10] D. Wu and D. C. Aliprantis, "Modeling light-duty plug-in electric vehicles for national energy and transportation planning," Energy Policy, vol. 63, pp. 419-432, 2013.

[11] N. Sathaye and S. Kelley, "An approach for the optimal planning of electric vehicle infrastructure for highway corridors," Transportation Research, Part E, no. 59, pp.15-33, 2013.

[12] G. Cardoso, M. Stadler, M.C. Bozchalui, R. Sharma, C. Marnay, A. Barbosa-Póvoa, P. Ferrão, "Optimal investment and scheduling of distributed energy resources with uncertainty in electric vehicle driving schedules," Energy, vol. 64, pp.17-30, 2014.

[13] N. Neyestani; M. Yazdani Damavandi; M. Shafie-khah; A. Bakirtzis; J. P. S. Catalao, "Plug-in Electric Vehicles Parking Lot Equilibria with Energy and Reserve Markets," IEEE Trans. on Power System, doi: 10.1109/TPWRS.2016.2609416.

[14] W. H. Kersting, "Radial distribution test feeders," Proc. IEEE Power Eng. Soc. Winter Meeting, 2001, vol. 2, pp. 908-912.

[15] Z. Liu, F. Wen, and G. Ledwich, "Optimal Siting and Sizing of Distributed Generators in Distribution Systems Considering Uncertainties," IEEE Trans. Power Del., vol. 26, no. 4, pp. 2541-2551, 2011.

[16] Y. G. Hegazy, M.M. Othman, W. El-Khattam, and A. Y. Abdelaziz, "Optimal sizing and siting of distributed generators using Big Bang Big 
Crunch method," Proc. International Universities Power Engineering Conference (UPEC), pp. 1-6, Sept. 2014.

[17] G. Pasaoglu, D. Fiorello, L. Zani, A. Martino, A. Zubaryeva, and C. Thiel, "Projections for Electric Vehicle Load Profiles in Europe Based on Travel Survey Data," European Comm. Rep. EUR 25993 EN, 2013, [Online]. Available: https://setis.ec.europa.eu/publications/jrc-setisreports.

[18] G. Pasaoglu, D. Fiorello, A. Martino, G. Scarcella, A. Alemanno, A. Zubaryeva, and C. Thiel, "Driving and parking patterns of European car drivers - a mobility survey", European Comm. Rep. EUR 25627 EN, 2012, [Online]. Available: https://setis.ec.europa.eu/publications/jrcsetis-reports.

[19] R. van Haaren, “Assessment of electric cars' range requirements and usage patterns based on driving behavior recorded in the National Household Travel Survey of 2009". Study of the Solar Journey USA. Earth and Environmental Engineering Department, Columbia University, Fu Foundation School of Engineering and Applied Science, New York, December 2011.

[20] Red Eléctrica de España, "Maximum average hourly power demand and daily energy," [Online]. Available: http://www.ree.es.

[21] A. Briones, J. Francfort, P. Heitmann, M. Schey, S. Schey, J. Smart, "Vehicle-to-grid(V2G) power flow regulations and building codes review by the AVTA," Idaho National Lab., Idaho Falls, ID, Sep. 2012, [Online]. Available: http://www1.eere.energy.gov.

[22] Y.K. Jemal, "Plug-in electric vehicle charging impacts on power systems," M.Sc. Thesis, Dept. of Energy and Environment, Chalmers Univ. of Tech., Goteborg, Sweden, 2010.

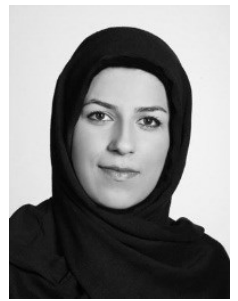

Nilufar Neyestani (S'09, M'14) received the M.Sc degrees in electrical engineering from Iran University of Science and Technology, Tehran, Iran in 2010 and Ph.D. from University of Beira Interior (UBI), Covilha, Portugal in 2016. She is currently a postdoctoral fellow at INESC TEC, Porto, Portugal. Her research interests include electric vehicles, smart grids, energy and reserve markets, power system optimization, multienergy systems and energy hub.

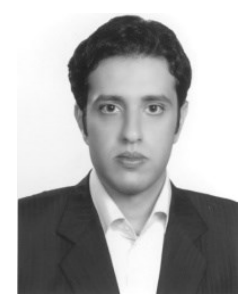

Maziar Yazdani Damavandi (S'08) received the M.Sc. degree in electrical engineering from the Tarbiat Modares University, Tehran, Iran, in 2010. He is currently pursuing his Ph.D. studies in the Energy Management laboratory in the Tarbiat Modares University (TMU) and working as a researcher in SiNGULAR project in University of Beira Interior (UBI), Covilha, Portugal. His research interests include optimization models in power system studies and multi-energy system modeling.

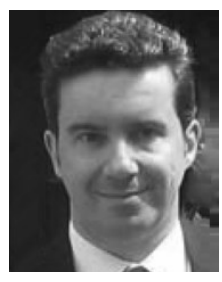

Gianfranco Chicco (M'98-SM'08) received the Ph.D. degree in electrotechnics engineering from Politecnico di Torino (PdT), Torino, Italy, in 1992.

$\mathrm{He}$ is currently a Professor of electrical energy systems with the Energy Department, PdT. His research interests include power system and distribution system analysis, energy efficiency, multigeneration, load management, artificial intelligence applications, and power quality.

Prof. Chicco is an Editor of the IEEE Transactions on Smart Grid, and a Member of the Italian Association of Electrical, Electronic, and Telecommunications Engineers.

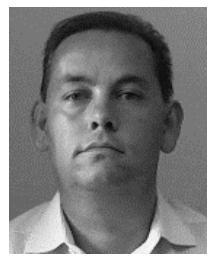

João P. S. Catalão (M'04-SM'12) received the M.Sc degree from the Instituto Superior Técnico (IST), Lisbon, Portugal, in 2003, and the Ph.D. degree and Habilitation for Full Professor ("Agregação") from the University of Beira Interior (UBI), Covilha, Portugal, in 2007 and 2013, respectively.

Currently, he is a Professor at the Faculty of Engineering of the University of Porto (FEUP), Porto,
Portugal, and Researcher at INESC TEC, INESC-ID/IST-UL, and CMAST/UBI. He was the Primary Coordinator of the EU-funded FP7 project SiNGULAR ("Smart and Sustainable Insular Electricity Grids Under LargeScale Renewable Integration"), a 5.2-million-euro project involving 11 industry partners. He has authored or coauthored more than 490 publications, including 168 journal papers, 283 conference proceedings papers, 23 book chapters, and 14 technical reports, with an $h$-index of 29 and over 3395 citations (according to Google Scholar), having supervised more than 45 postdocs, Ph.D. and M.Sc. students. He is the Editor of the books entitled Electric Power Systems: Advanced Forecasting Techniques and Optimal Generation Scheduling and Smart and Sustainable Power Systems: Operations, Planning and Economics of Insular Electricity Grids (Boca Raton, FL, USA: CRC Press, 2012 and 2015, respectively). His research interests include power system operations and planning, hydro and thermal scheduling, wind and price forecasting, distributed renewable generation, demand response and smart grids.

Prof. Catalão is an Editor of the IEEE TRANSACTIONS ON SMART GRID, an Editor of the IEEE TRANSACTIONS ON SUSTAINABle ENERGY, and an Associate Editor of the IET Renewable Power Generation. He was the Guest Editor-in-Chief for the Special Section on "Real-Time Demand Response" of the IEEE TRANSACTIONS ON SMART GRID, published in December 2012, and the Guest Editor-in-Chief for the Special Section on "Reserve and Flexibility for Handling Variability and Uncertainty of Renewable Generation" of the IEEE TRANSACTIONS ON Sustainable ENERGY, published in April 2016. He was the recipient of the 2011 Scientific Merit Award UBI-FE/Santander Universities and the 2012 Scientific Award UTL/Santander Totta. Also, he has won 4 Best Paper Awards at IEEE Conferences. 